\title{
Face masks for the public during the covid-19 crisis
}

\author{
Trisha Greenhalgh and colleagues argue that it is time to apply the precautionary principle
}

\author{
Trisha Greenhalgh professor ${ }^{1}$, Manuel B Schmid consultant ${ }^{23}$, Thomas Czypionka chief health \\ economist $^{45}$, Dirk Bassler professor ${ }^{2}{ }^{3}$, Laurence Gruer professor ${ }^{6} 7$
}

\author{
${ }^{1}$ Nuffield Department of Primary Care Health Sciences, University of Oxford; ${ }^{2}$ Neonatal Department, University Hospital of Zurich, Switzerland; \\ ${ }^{3}$ University of Zurich, Zurich, Switzerland; ${ }^{4}$ Institute for Advanced Studies, Vienna, Austria; ${ }^{5}$ London School of Economics, London, UK; ${ }^{6}$ University \\ of Edinburgh, UK; ${ }^{7}$ University of Glasgow, UK
}

The precautionary principle is, according to Wikipedia, "a strategy for approaching issues of potential harm when extensive scientific knowledge on the matter is lacking." The evidence base on the efficacy and acceptability of the different types of face mask in preventing respiratory infections during epidemics is sparse and contested. ${ }^{12}$ But covid-19 is a serious illness that currently has no known treatment or vaccine and is spreading in an immune naive population. Deaths are rising steeply, and health systems are under strain.

This raises an ethical question: should policy makers apply the precautionary principle now and encourage people to wear face masks on the grounds that we have little to lose and potentially something to gain from this measure? ? $^{3}$ We believe they should.

\section{Evidence and guidelines}

Evidence based medicine tends to focus predominantly on internal validity-whether primary research studies were "done right" - using tools to assess risk of bias and adequacy of statistical analysis. External validity relates to a different question: whether findings of primary studies done in a different population with a different disease or risk state are relevant to the current policy question. We argue that there should be a greater focus on external validity in evaluation of masks.

A rapid search of the literature on the wearing of masks by the general public during epidemics or pandemics by a team at the University of Galway (E Toomey, personal communication, 29 March 2020) found five peer reviewed systematic reviews:

- An "empty review" published on 27 March 2020 - that is, a review showing no randomised trials of masks so far during the covid-19 pandemic ${ }^{4}$

- A 2020 systematic review ${ }^{5}$ comparing standard surgical masks and respirator masks, which included a single small trial from 2009 of respirator masks, standard masks, and no masks among the general public during an influenza epidemic in Australia. ${ }^{6}$ That trial, which was considered robust, showed a benefit of masks over no masks, but no benefit of respirator masks over standard ones, and also showed that masks were worn less than $50 \%$ of the time

- A 2011 Cochrane review covering physical interventions and including 67 studies (many of poor quality), in which the main relevant study was the 2009 trial described above ${ }^{7}$

- A 2010 systematic review of face masks in influenza epidemics, which included standard surgical masks and respirator masks and found some efficacy of masks if worn by those with respiratory symptoms but not if worn by asymptomatic individuals. ${ }^{8}$

- A 2007 systematic review and expert panel deliberation, which acknowledged the difficulties in interpreting evidence and stated: "With the exception of some evidence from SARS, we did not find any published data that directly support the use of masks ... by the public." ${ }^{9}$ The evidence from SARS was not set out in the paper (so we assume it was expert opinion on the panel).

Two further systematic reviews have since been released as preprints. Xiao and colleagues reviewed non-pharmaceutical measures for prevention of influenza. ${ }^{10}$ They identified 10 randomised controlled trials published between 1946 and 2018 that tested the efficacy of face masks (including standard surgical masks and commercially produced paper face masks designed for the public) for preventing laboratory confirmed influenza. A pooled meta-analysis found no significant reduction in influenza transmission (relative risk $0.78,95 \%$ confidence interval 0.51 to $1.20 ; \mathrm{I}^{2}=30 \%, \mathrm{P}=0.25$ ). They also identified seven studies conducted in households; four provided masks for all household members, one for the sick member only, and two for household contacts only. None showed a significant reduction in laboratory confirmed influenza in the face mask arm. The authors concluded: "randomized controlled trials of [face masks] did not support a substantial effect on transmission of laboratory-confirmed influenza." ${ }^{10}$

A preprint of a systematic review published on 6 April 2020 examined whether wearing a face mask or other barrier (goggles, 
shield, veil) prevents transmission of respiratory illness such as coronavirus, rhinovirus, tuberculosis, or influenza. ${ }^{11}$ It identified 31 eligible studies, including 12 randomised controlled trials. The authors found that overall, mask wearing both in general and by infected members within households seemed to produce small but statistically non-significant reductions in infection rates. The authors concluded that "The evidence is not sufficiently strong to support the widespread use of facemasks as a protective measure against covid-19"11 and recommended further high quality randomised controlled trials.

\section{Contested interpretations}

The heterogeneous and somewhat sparse primary literature described above has been inconsistently interpreted by policy makers. The World Health Organization, for example, recommends masks only for those with symptoms suggestive of covid-19, stating that masks should otherwise be reserved for healthcare workers. ${ }^{12}$ However, elsewhere WHO acknowledges that the wearing of masks by the general public has a place in severe pandemics, since even a partial protective effect could have a major influence on transmission. ${ }^{13}$

The US Centres for Disease Control and Prevention originally advised the public against wearing masks during the covid-19 pandemic, but this advice was updated on 4 April 2020 (box 1). ${ }^{14}$

Box 1: CDC advice on use of face masks by the general public ${ }^{14}$ Cover your mouth and nose with a cloth face cover when around others You could spread covid-19 to others even if you do not feel sick Everyone should wear a cloth face cover when they have to go out in public-for example, to the grocery store or to pick up other necessities Cloth face coverings should not be placed on children under age 2 or on anyone who has trouble breathing or is unconscious, incapacitated, or otherwise unable to remove the mask without assistance.

The cloth face cover is meant to protect other people in case you are infected

Do not use a face mask meant for a healthcare worker

Continue to keep about 6 feet $(2 \mathrm{~m})$ between yourself and others. The cloth face cover is not a substitute for social distancing

None of the studies mentioned above tested the makeshift cloth masks that $\mathrm{CDC}$ has recommended. To our knowledge, there are no trials of cloth masks in the general public. A three arm trial of cloth masks versus surgical masks versus "standard practice" in preventing influenza-like illness in healthcare staff found that cloth masks were the least effective, but "standard practice" usually involved a surgical face mask and there was no true control arm with no masks. ${ }^{15}$

Various authors have justified not wearing masks on four main grounds. Firstly, they claim that there is limited evidence that they are effective. Secondly, they argue that trials have shown that people are unlikely to wear them properly or consistently, which is important since prevention depends on people not repeatedly touching their mask, and on all or most people wearing them most of the time. Thirdly, they point out that the trials cited above have also shown that wearing a mask might make people feel safe and hence disregard other important public health advice such as hand washing and social distancing. ${ }^{10}$ Finally, they argue that because of the shortage of masks in the current crisis, the public should not wear them since healthcare workers need them more, and public buying could lead to major supply chain problems. ${ }^{16}$

The first argument can be challenged on the grounds that absence of evidence is not evidence of absence. The second two arguments may have been internally valid in the trials that produced them, but we have no evidence that they are externally valid in the context of covid-19. "The public" here are not volunteers in someone else's experiment in a flu outbreak-they are people the world over who are trying to stay alive in a deadly pandemic. They may be highly motivated to learn techniques for most effective mask use.

There are good reasons why the public is likely to comply more closely with mask advice and wider infection control measures now than the research participants were in the published trials. These reasons include the fact that SARS-CoV-2 is both more contagious and more serious than the medical scenarios in the studies on which the conclusion not to use masks was based. ${ }^{17}$ Similarly, if SARS-CoV-2 vaccination were available and affordable, it might be used more widely and be more acceptable than flu vaccination.

Substantial indirect evidence exists to support the argument for the public wearing masks in the covid-19 pandemic. The virus has been shown to remain viable in the air for several hours when released in an aerosol under experimental conditions, ${ }^{18}$ and such aerosols seem to be blocked by surgical masks in laboratory experiments. ${ }^{19}$ Individuals have been shown to be infectious up to 2.5 days before symptom onset, ${ }^{20}$ and as many as $50 \%$ of infections seem to occur from presymptomatic individuals. ${ }^{21}$ Community prevalence of covid-19 in many countries is likely to be high. ${ }^{22}$ Modelling studies suggest that even a small reduction in community transmission could make a major difference to demand elsewhere in the system (eg, for hospital bed space and ventilators). ${ }^{23}$

The suggestion that the public should not wear masks because healthcare workers need them more is valid up to a point, but it is surely an argument for manufacturing more masks, not for denying them to populations who could potentially benefit from them. Until such masks are available in sufficient numbers, cloth masks (washed frequently) as recommended by the CDC (box 1), ${ }^{14}$ may be a substitute. Additional research is urgently needed to identify how best to overcome problems of poor filtration and moisture retention that have been described. Such studies could determine, for example, the optimum nature of fabric, thickness (how many layers?), the nature of the outer water repellent layer, closeness of fit, and duration to be worn before washing.

\section{Precautionary principle}

Anecdotal evidence is rightly viewed as methodologically suspect, but as we contemplate using the precautionary principle, we should not ignore such evidence entirely. We should, for example, take account of the high rates of infection (and substantial mortality) among healthcare and other frontline staff in settings where there are shortages of masks compared with settings where these staff were better and more consistently protected. ${ }^{24}$ We might come to regret dismissing as anecdote the story of a choir practice with 60 people, of whom 45 are known to have developed covid-19 and two so far have died. ${ }^{25}$

Some indirect evidence for the benefits of masks is emerging. For example, a longitudinal ecological study from Hong Kong, conducted before and after the introduction of a range of non-pharmaceutical measures including masks for the public, suggested that these seemed to help to contain the pandemic (changes were statistically significant for masks and social distancing measures combined, though the effect of masks alone cannot be isolated out). ${ }^{26}$ There is also analogical evidence from the behaviour of viruses with a similar chemical make-up. ${ }^{27} 28$

Given these indirect and circumstantial findings and the seriousness of this outbreak, there is a moral argument that the 
public should be given the opportunity to change their behaviour in line with the precautionary principle, ${ }^{3}$ even when direct, experimental evidence for benefit is not clear cut. Unlike in Australia and the US, where most trials were done, mask wearing has become normalised in some Asian countries, partly as a protection against polluted air and perhaps also as a response to the SARS and MERS outbreaks. In Japan, Hong Kong, South Korea, and China, for example, mask wearing is now the norm.

Another argument for using the precautionary principle is that the world may pay a high price for covid-19 and the "collateral damage" risks becoming higher than the direct damage from the virus. The dangers include increased suicide rates because of isolation and economic hopelessness among poorer people losing their income or in small companies, ${ }^{29} 30$ civil unrest in some countries when they consider lockdown, as was seen with Ebola,${ }^{31}$ people losing their access to their regular medication, ${ }^{32}$ thriving autocratic systems under the pretence of controlling covid-19, ${ }^{3334}$ and domestic violence and family disputes ${ }^{3536}$ - the list is long. There are, of course, important counterarguments, including the possibility of a false sense of security and reduction in compliance with other infection control measures.

We propose two hypotheses that we believe should be urgently tested in natural experiments. The first is that in the context of covid-19, many people can be taught to use masks properly and will do this consistently without abandoning other important anti-contagion measures. The second is that if political will is there, mask shortages can be quickly overcome by repurposing manufacturing capacity—something that is already happening informally. ${ }^{37}$

In conclusion, in the face of a pandemic the search for perfect evidence may be the enemy of good policy. As with parachutes for jumping out of aeroplanes, ${ }^{38}$ it is time to act without waiting for randomised controlled trial evidence. ${ }^{39}$ A recently posted preprint of a systematic review came to the same conclusion. ${ }^{40}$ Masks are simple, cheap, and potentially effective. We believe that, worn both in the home (particularly by the person showing symptoms) and also outside the home in situations where meeting others is likely (for example, shopping, public transport), they could have a substantial impact on transmission with a relatively small impact on social and economic life.

\section{Key messages}

The precautionary principle states we should sometimes act without definitive evidence, just in case

Whether masks will reduce transmission of covid-19 in the general public is contested

Even limited protection could prevent some transmission of covid-19 and save lives

Because covid-19 is such a serious threat, wearing masks in public should be advised

We thank the members of the covid-19 researchers Google group for a discussion which inspired this paper, though the views expressed in this paper do not reflect those of all group members. We also thank Elaine Toomey of Cochrane Ireland for sharing unpublished data from an ongoing review of face masks for the general public, and Sebastian Straube from University of Alberta, Canada, as well as two reviewers, Ben Cowling and Ka Hung Chan, for helpful advice on an earlier draft. We also thank three members of the public, John Taylor, Jenni Bowley, and Anica Alvarez Nishio, for useful feedback which helped us improve the paper.

Contributors and sources: The article was conceived on a professional discussion network. MBS wrote the first draft. TG added conceptual insights and coordinated shaping of the paper for BMJ. All authors contributed to the development of ideas and writing of the paper, and approved the final manuscript. TG and MBS are joint first authors and guarantors.

Competing interests: We have read and understood BMJ policy on declaration of interests and have no relevant interests to declare.

Provenance and peer review: Commissioned; not externally peer reviewed.

1 Feng S, Shen C, Xia N, Song W, Fan M, Cowling BJ. Rational use of face masks in the COVID-19 pandemic. Lancet Respir Med 2020;S2213-2600(20)30134-X. 10.1016/S2213-2600(20)30134-X 32203710

2 National Health Service (UK). Are face masks useful for preventing coronavirus? 2020. https://www.nhs.uk/conditions/coronavirus-covid-19/common-questions/

3 European Commission. The precautionary principle: decision making under uncertainty. 2017. https://ec.europa.eu/environment/integration/research/newsalert/pdf/precautionary principle_decision_making_under_uncertainty_FB18_en.pdf.

4 Marasinghe KM. A systematic review investigating the effectiveness of face mask use in limiting the spread of COVID-19 among medically not diagnosed individuals: shedding light on current recommendations provided to individuals not medically diagnosed with covid-19. Version 2. Research Square 2020.[Preprint.] 10.21203/rs.3.rs-16701/v2.https: //www.researchsquare.com/article/rs-16701/v2.

5 Long Y, Hu T, Liu L, etal . Effectiveness of N95 respirators versus surgical masks against influenza: A systematic review and meta-analysis. J Evid Based Med 2020. 10.1111/jebm.12381 32167245

6 Maclntyre CR, Cauchemez S, Dwyer DE, etal . Face mask use and control of respiratory virus transmission in households. Emerg Infect Dis 2009;15:233-41. 10.3201/eid1502.081166 19193267

7 Jefferson T, Del Mar CB, Dooley L, etal . Physical interventions to interrupt or reduce the spread of respiratory viruses. Cochrane Database Syst Rev 2011;7:CD006207. 10.1002/14651858.CD006207.pub4 21735402

8 Cowling BJ, Zhou Y, Ip DK, Leung GM, Aiello AE. Face masks to prevent transmission of influenza virus: a systematic review. Epidemiol Infect 2010;138:449-56. $10.1017 /$ S0950268809991658 20092668

9 Aledort JE, Lurie N, Wasserman J, Bozzette SA. Non-pharmaceutical public health interventions for pandemic influenza: an evaluation of the evidence base. BMC Public Health 2007:7-208, 10.1186/1471-2458-7-208 17697389

10 Xiao J, Shiu EYC, Gao H, etal . Nonpharmaceutical measures for pandemic influenza in nonhealthcare settings-personal protective and environmental measures. Emerg Infect Dis 2020;26. 10.3201/eid2605.190994 32027586

11 Brainard JS, Jones N, Lake I, et al. Facemasks and similar barriers to prevent respiratory illness such as COVID-19: A rapid systematic review. MedRxiv 2020.04.01.20049528 [Preprint] 2020 10.1101/2020.04.01.20049528

12 World Health Organisation. Advice on the use of masks in the context of covid-19: Interim guidance. 6 Apr 2020. https://www.who.int/publications-detail/advice-on-the-use-of-masksin-the-community-during-home-care-and-in-healthcare-settings-in-the-context-of-thenovel-coronavirus-(2019-ncov)-outbreak.

13 World Health Organisation. Non-pharmaceutical public health measures for mitigating the risk and impact of epidemic and pandemic influenza. 2019. https://www.who.int/ influenza/publications/public_health_measures/publication/en/.

14 Centers for Disease Control. How to protect yourself. 4 Apr 2020. https://www.cdc.gov/ coronavirus/2019-ncov/prevent-getting-sick/prevention.html?CDC_AA_refVal=https\%3A\% 2F\%2Fwww.cdc.gov\%2Fcoronavirus\%2F2019-ncov\%2Fprepare\%2Fprevention.html.

15 Maclntyre CR, Seale H, Dung TC, etal . A cluster randomised trial of cloth masks compared with medical masks in healthcare workers. BMJ Open 2015;5:e006577. 10.1136/bmjopen-2014-006577 25903751

16 World Health Organisation. Shortage of personal protective equipment endangering health workers worldwide. 2020. https://www.who.int/news-room/detail/03-03-2020-shortage-ofpersonal-protective-equipment-endangering-health-workers-worldwide

17 Fauci AS, Lane HC, Redfield RR. Covid-19-navigating the uncharted. N Engl J Med 2020:382:1268-9. 10.1056/NEJMe2002387 32109011

18 van Doremalen N, Bushmaker T, Morris DH, etal . Aerosol and surface stability of SARS-CoV-2 as compared with SARS-CoV-1. N Engl J Med 2020. 10.1056/NEJMc2004973 32182409

19 Leung NH, Chu DK, Shiu EY, etal . Respiratory virus shedding in exhaled breath and efficacy of face masks (brief communication). Nat Med 2020; [Epub ahead of print.] 10.1038/s41591-020-0843-2

20 Ferretti L, Wymant C, Kendall M, etal . Quantifying SARS-CoV-2 transmission suggests epidemic control with digital contact tracing. Science 2020;eabb6936. 10.1126/science.abb6936 32234805

21 Ganyani T, Kremer C, Chen D, et al. Estimating the generation interval for covid-19 based on symptom onset data. medRxiv 2020.03.05.20031815. [Preprint.] 10.1101/2020.03.05.20031815

22 Spellberg B, Haddix M, Lee R, etal . Community prevalence of SARS-CoV-2 among patients with influenzalike illnesses presenting to a Los Angeles medical center in March 2020. JAMA 2020 . 10.1001/jama.2020.4958 32232421

23 Hellewell J, Abbott S, Gimma A, etal. Centre for the Mathematical Modelling of Infectious Diseases COVID-19 Working Group. Feasibility of controlling COVID-19 outbreaks by isolation of cases and contacts. Lancet Glob Health 2020;8:e488-96. 10.1016/S2214-109X(20)30074-7 32119825

24 Gulland A. What is viral load and why are so many health workers getting sick? Daily Telegraph 2020 Mar 31. https://www.telegraph.co.uk/global-health/science-and-disease/ viral-load-many-health-workers-getting-sick/.

25 Read R. A choir decided to go ahead with rehearsal. Now dozens of members have COVID-19 and two are dead. Los Angeles Times 2020 Mar 29. https://www.latimes.com/ world-nation/story/2020-03-29/coronavirus-choir-outbreak? fbclid=IwAR0XyQu4gxJdPFVJpbZIOsX5EhX2VbQyxjakL1IVvITa-aCTHVaQgasIWss.

26 Cowling BJ, Ali ST, Ng TW, et al. Impact assessment of non-pharmaceutical interventions against COVID-19 and influenza in Hong Kong: an observational study. medRxiv 2020.03.12.20034660. [Preprint.] 10.1101/2020.03.12.20034660https://www.medrxiv.org/ content/10.1101/2020.03.12.20034660v1

27 Leung NH, Chu DK, Shiu EY, etal . Respiratory virus shedding in exhaled breath and efficacy of face masks. Nat Med 2020.10.1038/s41591-020-0843-2 
28 Lau JT, Tsui H, Lau M, Yang X. SARS transmission, risk factors, and prevention in Hong Kong. Emerg Infect Dis 2004:10:587-92. 10.3201/eid1004.030628 15200846

29 Gutman A. Coronavirus demands social distancing. Will that lead to more deaths of despair? Philadelphia Inquirer 2020 Mar 19. https://www.inquirer.com/health/coronavirus/ coronavirus-covid-19-deaths-despair-future-capitalis-angus-deaton-anne-case-20200319. $\mathrm{html}$

30 Weisbaum H. Millions of Americans will soon run out of money. Here's how to deal with bills you can't pay. NBC Universal, 2020. https://www.nbcnews.com/better/lifestyle/ coronavirus-collateral-damage-what-do-you-do-when-paycheck-stops-ncna1163671

31 Nyei A-bl. Beyond the disease: how the Ebola epidemic affected the politics and stability of the Mano River Basin. Conflict Trends 2016;2:12-9.

32 D'Amore R. "Collateral damage": wait times, cancellations hit health care outside of covid-19. Global News, 30 Mar 2020. https://globalnews.ca/news/6750377/coronaviruscanada-essential-health-care/

33 Woznicki K. On the edges of democracy: mobilizing health and care as a common good London: openDemocracy 17 Mar 2020. https://www.opendemocracy.net/en/can-europemake-it/edges-democracy-mobilizing-health-and-care-common-good/

34 For autocratic regimes, COVID-19 is a window to consolidate power. Newsday $2020 \mathrm{https}$ //www.newsday.co.zw/2020/04/for-autocratic-regimes-covid-19-is-a-window-to-consolidatepower/
35 Carrega C. Isolation of families for coronavirus raises concerns about domestic violence. ABC News 2020 Mar 20. https://abcnews.go.com/US/isolation-families-coronavirus-raisesconcerns-domestic-violence/story?id=69663886

36 Sharon K. Coronavirus complicates already-trying child custody issues. Orange County Register 2020 Mar 27. https://www.ocregister.com/2020/03/27/coronavirus-complicatesalready-trying-child-custody-issues/

37 Reagan C. Retailers shift production to make masks, gowns for health-care workers in coronavirus pandemic. CNBC Online 2020 Mar 26. https://www.cnbc.com/2020/03/26/ coronavirus-retailers-make-masksgowns-for-healthcare-workers.html.

38 Potts M, Prata N, Walsh J, Grossman A. Parachute approach to evidence based medicine. BMJ 2006;333:701-3. 10.1136/bmj.333.7570.70110.1136/bmj.333.7570.701 17008675

39 Smith GC, Pell JP. Parachute use to prevent death and major trauma related to gravitational challenge: systematic review of randomised controlled trials. Int J Prosthodont 2006;19:126-8.16602356

40 Jefferson T, Jones M, Al Ansari L, et al. Physical interventions to interrupt or reduce the spread of respiratory viruses. Part 1: face masks, eye protection and person distancing systematic review and meta-analysis. medRxiv 2020.03.30.20047217. [Preprint.] 10.1101/2020.03.30.20047217

Published by the BMJ Publishing Group Limited. For permission to use (where not already granted under a licence) please go to http://group.bmj.com/group/rights-licensing/ permissions 